\title{
Do sublime à leveza
}

Denilson Lopes*

\section{RESUMO}

No intuito de contribuir para uma estética da comunicação, procuramos desenvolver a atualidade da categoria do sublime no contexto contemporâneo, associando-a ao banal, ao cotidiano e a uma postura ética sustentada pela leveza.

\section{ABSTRACT}

In the search of contributing to an aesthelics of communication, we try to develop the actuality of the category of sublime in contemporary times, connecting it to the ordinan', to everyday life and to an ethic atitude based upon ligthness.

Denilson Lopes Coordenador do Programa de Pós-Graduaçāo em Comunicaçăo da Universidade de Brasilia. autor de Nós os Mortos: Melancolia e Neo-Barroco (RJ. Sette Letras, 1999) e O Homem que amava Rapazes e Outros Ensaios (RJ. Aeroplano, 2002), pesquisador do CNPq. 
Que destino teria a beleza hoje em dia? Seria o de Gustav von Aschembach em "Morte em Veneza"? Quanto mais ele procura a beleza, mais se aproxima da morte. Seria esta impossibilidade o destino do esteta hoje em dia? Ou seria antes, o puro prazer de voyeur perplexo, imobilizado como no poema "Sob o Duplo Incêndio" de Carlito Azevedo? Penso aindä em "Beleza Americana", o filme de Sam Mendes. Lester, o protagonista, ao se encantar por Angela, amiga de sua filha Jane, larga seu emprego, começa a fazer musculação, procura recuperar sua juventude. Ainda que esta cena seja tratada pelo diretor como ridícula, patética, é a partir desse momento que o protagonista se modifica. No mesmo filme, o jovem Ricky é quem mais parece traduzir a possibilidade transformadora da beleza na vida cotidiana. Ele filma o que o rodeia, buscando não só ser voyeur, mas estar no mundo. Ao relatar a Jane o que de mais belo tinha filmado, um saco que por 15 minutos volteava à sua frente, ele se aproxima como nunca até então de outra pessoa. É pela beleza que acontece esta possibilidade, por breve que seja, de estar no mundo, trata-se mais de uma intensidade do que dè uma elevação (LYOTARD, J.F.: $1988,111)$.

Falar da beleza não é apenas um discurso inútil, me coloca; ao mesmo tempo, no mundo novamente reencantado (BAUMAN, Z.:1997, 42) e na minha própria solidão, ao "reunir/cada fragmento nosso, perdido,/de dor e de delicadeza" (Carlito Azevedo, "Na Gávea"). Ou seria este desejo, isto tudo ilusão? A beleza e nada mais sigo.

Esta busca da beleza passa primeiro pelo elogio, pelo retorno do sublime seja como programa, seja como provocação. Me vejo inapelavelmente impelido a recuperar a estética, não mais colonizada pela economia, pela política. Estaria mesmo todo sentimento de encantamento e fascinio diante do mundo, das pessoas reduzido a mero olhar de consumidor, marcado por padrões publicitários, que encobrem a realidade? É necessário mesmo uma viagem de redescoberta, de reaprendizado, sem medo da beleza uma vez mais, sem confundir estética com esteticismo, salões de beleza ou academias de musculação, uma viagem como a que o poeta Basho fez em "Trilha Estreita ao Confim" apenas para contemplar a lua cheia nascendo sobre as montanhas do santuário de Kasima.

Mas o que fazer quando nosso cotidiano se transformou em experiência midiática, audiovisual? Acelerar, ir mais rápido, ser mais veloz, aderir ao simulacro ou estabelecer pausas, silêncios, recolhimento? Opto agora pelo sublime. O sublime não só como uma experiência, bastante recorrente dentro da história da filosofia, mas sobretudo uma categoria de articulação das obras contemporâneas.

Meu objetivo é o de problematizar o tema do sublime como possibilidade da experiência estética. Sem me alongar, parto de uma primeira e precária definição do sublime. O sublime seria a experiência entre horror e 
prazer, experiência de fascinio diante de uma paisagem, uma pessoa ou uma obra de arte, como nos lembra Nelson Brissac Peixoto (1997, 301/2), é "o impensável, o indiscernivel", "evidência de algo que não podemos ver nem definir mas que nos arrebata", "desejo indeterminado e imenso", "o inomeável, inenarrável".

Para além de nos determos na trajetória desta categoria' a partir da discussão no mundo latino (Longino, Cecilio, Plotino), nos séculos XVIIl e XIX, sobretudo na filosofia alemâ (Kant), no Romantismo, e mais recentemente sua retomada, entre outros, por Lyotard, só ressalto o que interessa para discutir sua atualidade hoje em dia. Se para Longino $(1996,18)$, o sublime é "o eco da grandeza da alma". Esta aproximação do sublime com o grandioso continua para além do caráter épico presente em Longino, até em Kant (1995, 93), ao remeter ao absolutamente grande, ou nos românticos, ao fascinio pelo indefinido, mas já em Burke (s.d.,78 e 84), há simultaneamente a associação do sublime com a infinitude, a magnificência, mas também se abre uma outra tradição, bastante fecunda na modernidade, ao associar o sublime com o extremamente pequeno, possivel de ser identificado posteriormente, por exemplo, na memória involuntária de Proust. $\dot{A}$ medida que cada vez mais o grandioso, o monumental pode ser associado à arte dos vencedores, de impérios autoritários, do nazismo ao stalinismo aos épicos hollywoodianos, é justamente no cotidiano, no detalhe, no incidente, no menor que residirá o espaço da resistência, da diferença.

Uma primeira aproximação seria possível entre o sublime e o sagrado.

Tanto o êxtase mistico quanto o sublime são marcados por uma suspensão e uma dificuldade em nomear o vivenciado, experiências que podem ser vistas como análogas ao orgasmo ${ }^{2}$ e à própria busca da arte moderna em representar o irrepresentável, em transgredir os limites, transitar entre o ruido e o silêncio, explorar o fora da tela, das galerias, o fora do palco.

Mas apesar do sublime ser fruto da passagem de uma sociedade centrada em Deus e na religião como aparato institucional para uma sociedade laica, há uma perda do privilégio do encantamento diante dos santos e deuses para que o mundo material possa também ser fonte desta experiência. $O$ sublime, afastado de um dimensão metafísica, dualista, não implica a negação do mundo, do corpo e dos sentidos em favor do espírito. Sem dúvida, se trata de uma suspensão, mas se não podemos viver $\mathrm{em}$ constante encantamento $\mathrm{e}$ fascínio, aprendemos algo desta suspensão? O que nos resta depois do gozo, a não ser talvez lembrar o sentido? Ou ainda, a experiência do sublime poderia ser imemorial em meio a transitoriedade de tudo? Sua própria força estaria não em uma transcendência, mas num mergulho mesmo no mundo das coisas, no aqui e no agora (LYOTARD, J.F.: 1988, 104). 
Mas longe de localizar o sublime apenas numa tradição canonizadora do moderno, conservadora, nostálgica de sentidos em meio à rapidez das imagens e máscaras, como talvez seja o caso de Lyotard ao eleger o pintor abstrato Barnett Newman quando resgata o sublime em busca de uma "estética desnaturada, portanto negativa" $(1993,69)$, mais próxima á alta modernidade do que diante da condição pós-moderna que outrora defendia, acredito e aposto numa linhagem do sublime, em tom menor, no cotidiano, em personagens comuns, presente na poesia de Manuel Bandeira e na crônicas de Rubem Braga, como bem a mapeou Davi Arrigucci $(1990,1987)$, e se desdobra, num desejo de revalorização da narrativa como forma de se aproximar do público, de se aproximar do mundo contemporâneo, seja no cinema, seja na literatura, de Kiarostami, Wong Kar Wai, Kieslowski a Mike Leigh, Hal Hartley, do último Almodóvar a Terence Davies, em Kazuo Ishiguro, David Leavitt e Michael Cunninghan, entre nós, em Walter Salles e Eduardo Coutinho, Adriana Lisboa e Rubens Figueiredo. Trata-se da possibilidade de uma experiência de beleza que emerge de um cotidiano povoado de clichês, implica repensar o banal. Possibilidade esta que me interessa mais.

O sublime no banal não se confunde com uma busca de uma autenticidade perdida no mundo da reprodutibilidade técnica e eletrônica da imagem, da aura benjaminiana, aproxima-se do que Ítalo Moriconi (1998) chamou de dessublimação, ao incorporar o corporal, mas talvez por não compartilhar o mesmo solo cultural de onde suas reflexões parecem emergir, marcadas pela contracultura, 90 pelo desbunde e pela poesia marginal, me distancio de qualquer possibilidade iconoclástica, de virulência trransgressora, mesmo que paródica. $O$ sublime no banal estabelece mais um jogo de tensões entre a contemplação e o olhar distraído, a rapidez e a lentidão e prefere apostar mais na sutileza, na delicadeza, na leveza, nas palavras que não canso de repetir de Ana Chiara (1999), "sem muito desespero, que é inútil, sem pieguice, que é meio de mau gosto, sem cinismo, porque já basta a desrazão, mas com suave ironia para poder suportar o peso".

Este sublime se encontra traduzido exemplarmente no último filme de Rafael França, "Prelude to Announced Death", concluído pouco antes de sua morte. Abraços e toques se sucedem entre dois homens de quem não vemos os rostos. Ou é do que me lembro. Nomes atravessam a tela. Não uma lista de pessoas, mas sucessão de lembranças. $\mathrm{Na}$ ansiedade do encontro e da despedida anunciada no título, não há mais tempo para memórias detalhadas, falas longas, elaboradas, só flashes de nomes e gestos. Nada para ser dito ou falado a não ser tocar. As pessoas restam em nomes. Antes de serem perdidos, esquecidos. Não se trata de saciar um último desejo. Não há tanto frenesi. Não há sexo, orgasmo. Apenas a superficie da pele se apresenta simplesmente, como se pudesse reter pela delicadeza, dizer.

Seria o sublime, portanto, um enobrecimento do banal, dar ênfase, foco ao que não tem? Sem dúvida, o sublime se situa no quadro em que a arte 
foi se tornando cada vez mais um conceito ampliado e complexo, em que a beleza se afastou de objetos específicos. Tudo pode ser belo, mesmo um cadáver no famoso poema de Baudelaire. Qualquer coisa pode ser arte, como nos impactou Duchamp. Todo mundo pode ser artista, como reafirmaram os punks. Mas hoje, não se trata tanto de uma militância virulenta, mas de produzir sentidos precários, recolher cacos, vestígios, habitar ruínas. Não esperar a revelação, a epifania, a iluminação, nem idealizar o simples, o cotidiano, mas certamente desmistificar o grandioso, o momumental. Nesta forma, o sublime não se apresentaria como, em críticas originárias dos estudos culturais, "espaço da reconciliação burguesa", que implica a volta à estética como produtora de hierarquias e distinções (DELFINO, S. : 104), nem como "oposto ao sentimento de solidariedade social" (HEBDIGE, D.: 1998, 141), por "atomizar a sociedade ao confrontar cada individuo com a perspectiva de sua própria destruição iminente e solitária" (idem, 137)

O sublime seria uma experiência aristocrática? Seria mais uma experiência daqueles que têm tempo. Seria o tempo um privilégio de classe? Mas também os que têm muito dinheiro estão muitas vezes interessados em gastar sem tempo em terem mais ou manter o que têm. O sublime certamente implica uma outra relação com o mundo não marcado exclusivamente pelo trabalho e pela produção. Como produzir imagens e narrativas que ainda tenham força diante do excesso informacional? É possivel falar em um "sublime tecnológico", não apenas como "objeto de uma produção controlada e de um consumo socializado" (COSTA, M.: 1995, 49), como se as novas tecnologias por si instaurasssem um nova situação material (idem, 37), mas no momento em que os meios de comunicação de massa não são elementos externos, são cotidiano, memória e afeto, como no romance "Onde Andará Dulce Veiga?" de Caio Fernando Abreu, mergulhamos numa atmosfera em que o sujeito humanista se dissolve, seu excesso se esvazia.

Há mais de 20 anos, Roland Barthes falava da solidão do discurso amoroso em uma sociedade centrada cada vez na sexualidade. Talvez a estética tenha se tornado uma outra solidão. Todos falam de cultura, mercado. Sim, é claro, isto ajuda a compreender mas não esgota o encantamento, a perdição desta experiência: o sublime. Falar do sublime não para ter saudade de algo que nós perdemos, mas algo que podemos encontrar quando menos esperamos, sobretudo quando não esperamos mais nada. Nada de mais grandioso, transcendental, mas menor, banal, cotidiano, concreto, material. O sublime é uma alternativa tanto ao discurso fatigado das transgressões tardomodernas que artistas perfomáticos, cineastas experimentais insistem $\mathrm{cm}$ ressuscitar quanto diante de um mundo povoado de imagens, clichês e informações, não para recusá-lo, mas de dentro dele afirmar uma adesão ao mundo. Como nos provoca Nelson Brissac Peixoto: "o destino das imagens não está mais sendo jogado no experimentalismo da vanguarda nem no 
engajamento ideológico, discursos completamente integrados no sistema de produção de clichês. O futuro das imagens está na produção do sublime" (PEIXOTO, N. B.: 1997, 318). O sublime midiático, tecnológico, o sublime pop. O sublime não como fuga do mundo, escapismo, mas afirmação da possibilidade do encontro, da presença.

O sublime se constitui a base de uma educação dos sentidos a partir do precário, do fugaz, do contingente, de tudo que evanesce rápido, mas que brilha inesperada e sutilmente. Um tesouro para ser guardado.

O sublime faz da arte uma ambiência, uma paisagem onde se pode habitar e caminhar lentamente como se houvesse o tempo todo do mundo, é a volta ao torno de um lago que bem pode ser uma vida, é o retorno ao mar, ao indefinido, ao inumano. Se for engano, ilusão, que seja então. Talvez todo este esforço tenha sido em vão. Por que buscar renomear, torcer uma palavra com sentidos tão arraigados? Por que não falar em outra palavra: leveza?

O sublime aqui se traduz num posicionamento ético e estético diante do mundo frente ao populismo midiático sem ignorar os meios de comunicação mas pensá-los em sua diversidade. Pensar os frágeis limites entre o sublime e o banal implica recolocar a atualidade ou não de uma estética hoje em dia. Em contraponto a um discurso da negação e de transgressão, reduzido hoje a uma estratégia de marketing, defendo uma gentil subversão. Também em contraponto a uma estética da violência, ao fascínio pelo grotesco e pelo abjeto, o sublime se traduz em leveza e delicadeza. Não consigo deixar de 92 pensar no primeiro princípio da estética de Nietzsche $(1999,11)$ : "O que é bom é leve, tudo divino se move com pés delicados".

Como falar de leveza hoje em dia? Perder peso seria uma adesão à velocidade ou possibilidade de pausa? Parto da idéia simples de que a leveza estabelece um diálogo constante com o peso, para que saibamos tanto voar como cair, tanto mover como repousar (ver BACHELARD, G.: 2001. 22), e para além de avaliações subjetivas, de gosto, ela se apresentaria mais como um destino, uma procura, do que um conceito rigoroso. A partir de algumas imagens, podemos contar estórias e impressões que envolvem sua defesa, sem nunca aprisioná-la. Defini-la seria como querer pegar água com as mãos. O melhor sempre escorre. Talvez um método, um caminho melhor, como nos lembra Ítalo Calvino, seria não olhá-la de frente, sem esquecer de que há uma presença indelével em tudo que se possa falar sobre a leveza.

Me vejo de repente, sempre à procura da leveza, primeiro na melancolia, "a tristeza que se tornou leve" (CALVINO, I.: 1997, 32), agora , o que acabo de chamar como sublime no banal, um sublime em tom menor, um mergulho no esquecimento, memória evanescente, recusa do ressentimento, renascer no devaneio que é o sonho tornado leve. Diferente do sublime que possui uma espessura filosófica, a leveza ainda não tem. Talvez por isso mesmo, podemos entendê-la mas como uma categoria que emerge sobretudo 
dos discursos poéticos, mesmo quando são de pensadores como Nietzsche, Bachelard e Serres.

O mérito de Calvino ao colocar a leveza como o primeiro valor a ser preservado no nosso milênio se traduz numa lição de humildade e de generosidade, para só levarmos o essencial, o que pudermos carregar, e o resto deixarmos de lado (CALVINO, 1.: 1997, 41). Na sua mais bela palestra, Calvino defende a leveza, de forma bastante concreta, que implica mesmo procedimentos formais, como um despojamento da linguagem (talvez contra toda uma literatura barroquizante, de excessos), o uso de uma narração sutil ou de uma descrição de alto poder de abstração e busca de uma imagem figurativa que se transforme num emblema (idem, 29/30).

Ao considerar a leveza de forma positiva, Calvino já se diferencia de toda arte que confunde peso com importância, densidade com sisudez. Calvino tem até um certo pudor ao afastar a leveza do pensamento, “a vivacidade c a mobilidade da inteligência" (idem, 19) da mera leviandade, superficialidade (idem, 22), como depois, em outra palestra, terá em elogiar a rapidez, definida pela agilidade, desenvoltura, mobilidade, sem negar os prazeres do retardamento (idem, 59), nem se deixar confundir com mera vertigem midiática que reduz tudo e homogeneiza tudo (idem, 58). O mais importante é que radicaliza as conseqüencias de tirar o peso da coisas, lugares e personagens como estratégia para resgatar a narrativa de todos aqueles que a vêem morta, sem sentido.

Mas para além de questões formais, a leveza representa um esiar diferenciado no mundo. Por mais que haja um drama da leveza como nos lembra ao falar de Milan Kundera sobre uma leveza que perdoa tudo, mesmo as maiores atrocidades históricas sob o véu da nostalgia (KUNDERA, M.: 1985,10 ), sobre a insustentável leveza do ser no protagonista de seu romance mais conhecido, que acaba por se transformar num "inelutável peso do viver" (CALVINO, 1.: 1997, 19), há uma alegria ao resgatar a narrativa como capaz de lidar com o mundo que nos escapa entre os dedos, diante de nós. Trata-se de buscar uma nova aventura tão antiga como as lendas e mitos, tão nova como o mundo da informação, um mistério que emerge mesmo da um mundo transparente e claro. Existe um designio solar neste resgate, um fascinio diante do mundo tal qual ele é, por mais maravilhosas, fantasiosas, incomuns que sejam algumas das ficções de Calvino. Ou mesmo em resgatar a história "tão leve quanto a vida do individuo, insustentavelmente leve, leve como uma pluma, como uma poeira que voa, como uma coisa que vai desaparecer amanhã (KUNDERA, M.: 1985, 224).

A leveza de Calvino é uma força menor, para brincar com o livro $A$ Força Maior de Clément Rosset, uma prima modesta da alegria nietzscheana, mais discreta, menos trágica, menos marcada pelo discurso da potência e mais pelo da sutileza. Se o eterno retorno evoca uma dimensão trágica, a leveza de algo que não volta resulta em colher insignificâncias, levar a brincadeira a sério, sem temer o sentimentalismo, por sabermos que "antes de 
sermos esquecidos, seremos transformados em kitsch. O kitsch é a estação intermediária entre o ser e o esquecimento" (KUNDERA, M.: 1985, 279). Como na ascensão final dos protagonistas em fuga de "Paraíso" de Tom Tykwer (2002), a partir de roteiro de Kieslowski, como um belo exemplo de alegria áerea, que é sobretudo a liberdade (BACHELARD, G.: 2001, 136). Tantos momentos, encontros. Tantas fugas, pausas. Estes e os que hão de vir. Agora e aqui, suspenso no ar transparente. Apenas uma luz emerge pura, como no início dos tempos. O dia avança. Nada a desejar a não ser o mover imóvel no helicóptero. Todos os anos passados e por vir se elevam. Não evanescem, se concentram. Todas as horas, todos os sentimentos, amor e desamor. "Através de nossos corações, que conservamos abertos,/passa o deus, asas nos pés (RILKE, R. apud BACHELARD, G.: 2001,34). A alegria aérea também por ser vista como a superação do medo do vôo, uma libertação do passado, como no belo trabalho, "A Arte de Subir em Telhados" da Armazém Companhia de Teatro. Para um terrestre tudo se dispersa e se perde ao deixar a terra, para um aéreo tudo se reúne, tudo se enriquece ao subir (BACHELARD, G.: 2001,50).

A leveza está mais próxima do prazer barthesiano (BARTHES, R.: $1999,7)$ que se desloca sem cessar, para não se acomodar, reificar, que ao invés de enfrentar, como Perseu diante da Medusa (CALVINO, I.: 1997, 16/7), muda de posição mas não deixa de olhar a monstruosidade da realidade. Ao invés da simples fuga, a leveza é mais um mergulho no mundo. Frente a uma arte do estardalhaço e do escândalo, na mídia, nas polêmicas, a discrição 94 como prática, traduzida de forma exemplar em "Nelson Freire" de João Moreira Salles (2003). O silêncio e a cegueira aparecem não como negação do mundo mas forma de ouvir melhor, ver melhor. "Não quero fazer guerra ao que é feio. Não quero acusar, não quero nem mesmo acusar os acusadores. Que a minha única negação seja desviar o olhar! E, tudo somado em suma: quero ser, algum dia, apenas alguém que diz Sim!" (NIETZSCHE, F. 2002, 188). Uma posição discreta, não do cínico ou cético distante, mas de um companheiro de jornada, que não vai nem na frente, nem atrás, apenas ao lado, solidário.

Até onde pode levar a leveza? Como saber se ela não acabou. Ainda. E por todos os dias e horas que virão, não se deixar abater antes do tempo. Ter ainda a curiosidade da criança, do viajante, do anjo, estes mensageiros da leveza no nosso mundo. Sem saber do que virá, mas buscar a força do presente, das coisas do mundo. Por mais que tudo tenha passado rápido demais foi este o momento e não outro. Há uma salvação pelas fragilidades e precariedades, não por verdades acabadas, sistemas fechados, pesados. Por mais que o mundo nos pese, ainda resta uma brecha, nem que seja para rirmos de nós mesmos, de onde estamos, até onde caímos. E neste riso, num gesto tolo, num ato gratuito, voa algo que não se pode prender.

Mas afirmar a leveza não seria afirmar o mundo da rapidez, da informação e da ausência da memória? A leveza apenas diria do mundo como 
ele é e cada vez mais é? Sem amarras, soltos e sós, mariposas esvoaçando batendo umas contra as outras e contra a luz até que não haja mais luz? Talvez, mas pensaria numa outra imagem, da mariposa que a cada batida deixa partes de seu corpo até não ser mais que luz, incêndio e cinzas. Quem haveria de dizer que seria de todo em vão, se houve tanta violência, mas tanta beleza, no caminho, até o fim? Nós que como Calvino, somos melancólicos em busca da alegria, saturninos que desejamos ser mercuriais (CALVINO, I.: 1997, 65), poderíamos pedir modestamente, todos os dias, "mais leveza", como uma promessa e prece, presença e utopia.

Haveria uma leveza na rapidez, uma leveza da dissolução, em que o próprio movimento rarefaz qualquer possibilidade de contato, ou pelo menos reduz tudo ao movimento. Do Futurismo a filmes como "Corra, Lola, Corra" de Tom Tykwer (1999) muito haveria para se dizer. Talvez a simples celcbração da velocidade como império da máquina seja dificil de se sustentar hoje em dia, mas há o fascínio, o êxtase mesmo da diluição, no ritmo mesmo acelerado de qualquer festa, dança, celebração, como na casa noturna, ouvindo gradualmente a intensidade da música até entrar, em "Millenium Mambo" de Hou Hsiao Hsien (2001). Esta leveza na rapidez pode também se radicaliza na leveza da viagem, no se deixar ser estrangeiro, sem raizes, ser outro constantemente até se perder, como em tantos road movies, como "O Passageiro" de Antonioni (1973). Para além da melancolia, a alegria estrangeira, usada por Julia Kristeva (1994) em outro contexto, que faz do próprio exilio, desterramento, uma espécie de encontro, um pertencimento aéreo, uma casa móvel, mais gregária do que geográfica.

Se Calvino preferia a leveza do pássaro à leveza da pluma, preferindo a precisão e a determinação em detrimento do vago e do aleatório (CALVINO, I.: 1997,28), poderiamos pensar mais as duas levezas como complementares. A leveza do pássaro como uma leveza da ação, da vontade afirmada, da narrativa precisa, do trajeto estabelecido, que vê de uma certa distância, transformando a paisagem em mapa, enquanto a leveza da pluma no ar, da espuma no mar é a leveza da deriva, mais incerta, mais cheia de surpresas e marcada pelo acaso, no seu próprio caminho, leveza que aceita a realidade de perto, sem restrições e ainda sim se alegra, tão presente nas manifestações que incorporam o acaso, o momentâneo, o fugaz.. Mas não só.

Esta segunda leveza decorre mesmo da pausa, do silêncio. Há muito ruido, desejo de comunicação travestido de excesso de informação. A leveza no cotidiano, do pequeno gesto, das pequenas coisas. $A$ leveza que aguarda e guarda o mundo na sua impureza. "Guardar uma coisa não é escondê-la ou trancá-la./(...) Guardar uma coisa é olhá-la, fitá-la, mirá-la por/admirá-la, isto é, iluminá-la ou ser por ela iluminado./(...) Por isto melhor se guarda o vôo de um pássaro/Do que um pássaro sem vôos" (CICERO, A.: 1996, 11). Leveza presente mesmo em meio ao maior descontrole. Em meio ao delirio, do mundo, caminhar 
como á beira de um lago plácido. Não indiferença, mais uma inocência, um destino ou uma escolha, uma conquista quando nada mais esperamos, quando já sofremos o peso da existência. Na serenidade heideggeriana, ao deixarmos ser atravessados pelo mundo sem que nos dissolvamos ou na meditação zen budista que intensifica o estar no mundo, imprimimos uma direção discreta, como numa tempestade em alto mar, em que se debater em demasia, fazer mais, pode apenas antecipar o naufrágio. Saber flutuar, se posicionar em meio à deriva, uma meta. Insistir uma vez mais diante da sedução do peso, do êxtase do naufrágio. Levantar os olhos quando toda a realidade parece ser o fundo, a queda. Esquecer para poder se deslocar, se desvencilhar do peso das mágoa, ressentimentos, do passado, da perda como em "Doce Amanhã" de Atom Egoyan (1999). A criança é o pai do homem sereno, é um reaprender, quando podiamos nos afundar e ousamos voar, como um Ariel liberto do Próspero, é parte dele mesmo que se liberta.

A leveza é o antídoto da melancolia. Frente a dor suave, do passado que não passa, a modesta alegria simplesmente por viver, não por ter ganho algo. Não resistir ao apequenenamento das coisas e pessoas. $O$ retrato embaçado. A água saindo pelo ralo. A poça onde antes era um mar. Um momento onde antes era toda a vida, o que importava. A leveza da deriva, a liberdade frente ao peso da orfandade. Vestígios de desejos tardiamente percebidos. Encanto ao conseguir lembrar feliz as perdas. Suave delicadeza de um ocaso. "Antes de desaparecer totalmente do mundo, a beleza existirá 96 ainda alguns instantes, mas por engano. A beleza por engano é o último estágio da história da beleza" (KUNDERA, M.: 1985, 107). Assim, se faz uma última imagem da leveza, ao ser associada a uma filosofia do apagamento (BACHELARD, G.: 2001, 171), a um retornar. "O mundo é belo antes de ser verdadeiro. O mundo é admirado antes de ser verificado" (idem, 169), mundo de "extrema solidão em que a matéria se dissolve, se perde" (idem, 171)

A felicidade fácil nada prova a não ser a generosidade da vida para quem a recebe. Ser feliz em meio a tormentas é o desafio e o aprendizado. Quando nada ou pouco satisfaz, retirar a força da dor. Sorrir diante da luz que cega. Cantar quando o tapa humilha. Caminhar delicadamente diante das vaias. Diante do abismo resistir ao mergulho na loucura, no suicídio, no útero da morte. Caminhar diante do peso das coisas, com a leveza na alma.

\section{Bibliografia}

AGEL, Henri. El Cine y lo Sagrado. Madri, Rialp, 1960. . O Cinema tem Alma? Belo Horizonte, Itatiaia, 1963.

ARRIGUCCI, Davi. "Ensaio sobre 'Maçã' (Do Sublime Oculto)" in: Humildade, Paixão e Morte. A Poesia de Manuel Bandeira. São Paulo, Companhia das Letras, 1990. 
1987.

Enigma e Comentário. Sào Paulo, Companhia das Letras,

AZEVEDO, Carlito. Sublumar (1991-2001). Rio de Janeiro, 7 Letras, 2001.

BACHELARD, Gaston. O Are os Sonhos. 2 ed., São Paulo, Martins Fontes, 2001.

BARTHES, Roland. O Prazer do Terto. $5^{5}$ ed., São Paulo, Perspectiva, 1999.

BASHO. Trilha Estreita ao Confim. São Paulo, lluminuras, 1997.

BAUMAN, Zygmunt. Ética pós-moderna. São Paulo, Paulus, 1997,

BENJAMIN, Walter.Magia e Técnica, Arte e Politica. São Paulo, Brasiliense, 1985.

BURKE, Edmund. Uma Investigação Filosófica sobre a Origem de Nossas

Idéias do Sublime e do Belo. Campinas, Papirus.

CALVINO, İtalo. Seis Propostas para o Próximo Milêntio. $2^{`}$ ed., São Paulo, Companhia das Letras, 1997.

CHIARA, Ana. "Geografia dos Afetos" in MORICONI, Italo (org.). Op. Cit. MORICONI, Ítalo (org.). Caio Fernando Abreu - Palava e Pessoa. Manuscrito Inédito, 1999.

COSTA, Mario. O Sublime Tecnológico. São Paulo, Experimento, 1995.

DANTAS, Rodrigo (org.). Belo. Sublime e Kant. Belo Horizonte, Ed. UFMG, 1998.

DELFINO, Sílvia. "La Trivialidad de lo Sublime", XYZ - Revista de Comunicación, 1, 1, febrero 1997.

FERRATER MORA, José. Diccionario de Filosofia. Barcelona, Ariel, 1994.

FERRAZ, Eucanâa. Desassombro. Rio de Janeiro, 7 Letras, 2002.

GLUCKSMANN, Christine Buci-. L'Oeil Carlographique de L'Art. Paris, Galilée, 1996.

GONZALES, Horacio. "Experiencia y Acontecimiento. Cinco Aforismos", $L a$ Invencion y La Herencia. Cuademos Arcis, 6, junho 1998.

HEBDIGE, Dick. "El Objeto Impossible: hacia una sociologia de lo sublime" in CURRAN, James et al. (orgs.). Estudios Culturales y Commuicación. Barcelona/Buenos Aires/México, Paidós, 1998.

HEIDEGGER, Martin. Serenidade. Lisboa, Instituto Piaget.

KANT, Emmanuel. Critica da Faculdade de Juizo. $2^{-}$ed., Rio de Janeiro, Forense, 1995.

Observaçós sobre o Sentimento do Belo e do Sublime.

2`ed., Campinas, Papirus, 2000.

KRISTEVA, Julia. Estrangeiros a nós mesmos. Rio de laneiro, Rocco, 1994.

KUNDERA, Milan. A Insustentavel Leveza do Ser. $20^{\star}$ ed., Rio de Janeiro, Nova Fronteira, 1985.

LONGINO. Do Sublime. São Paulo, Martins Fontes, 1996.

LYOTARD, Jean François. L'Inhumain. Paris, Galilée, 1988.

. Lições sobre a Analitica do Sublime. Campinas,

Papirus, 1993. 
MORICONI, Ítalo. "Quatro $(2+2)$ Notas sobre o Sublime e a Dessublimação", Revista Brasileira de Literatura Comparada, 4, 1998. . "Pós-Modernismo e a Volta do Sublime" in PEDROSA, Célia er al. (orgs.). Poesia Hoje. Niterói, Eduff, 1998.

NIETZSCHE, Friederich. Assim Falava Zaratustra. São Paulo, Hemus, 1979.

Paulo, Companhia das Letras, 1999. . O Caso Wagner. Nietzsche contra Wagner. São

Letras, 2002. . A Gaia Ciência. São Paulo, Companhia das

PEIXOTO, Nelson Brissac. "Ver o Invisível: a Ética das Imagens" in NOVAES, Adauto (org.). Ética. 5a. reimpressão, São Paulo: Companhia das Letras, 1997. ROLFE, Jeremy Gilbert-. Beauty and the Contemporary Sublime. New York, Allworth, 1999.

ROSSET, Clément. A Alegria. A Força Maior. Rio de Janeiro, Relume Dumará, 2000.

SERRES, Michel. A Lenda dos Anjos. São Paulo, Aleph, 1995.

\footnotetext{
Notas

' Para uma discussão mais filosófica entre nós, ver, por exemplo Rodrigo Dantas (1998)

${ }^{2}$ Sendo comum o uso de metáforas eróticas na literatura mística e de metáforas sacras na literatura erótica.
}

\section{Palavras-chave}

1. Sublime

2. Leveza

3. Estética

4. Beleza

5. Experiência 